\section{COMPARISON OF CAPABILITIES OF FINITE ELEMENT METHOD AND SPECIALIZED SOFTWARE PROGRAMS IN EVALUATION OF GEARS}

VACLAVA LASOVA, PETR BERNARDIN, EVA KRONEROVA

University of West Bohemia, Faculty of Mechanical Engineering,

Department of Machine Design, Pilsen, Czech Republic

DOI: 10.17973/MMSJ.2015_06_201515

e-mail: lasova@kks.zcu.cz

When performing the evaluation of engineering structures, today's designers fully depend on software tools available to their employer. The choice of a software program for design calculations and evaluation of structural elements is typically dictated by its price. Where the demand for engineering design services involves simple structures, the designers turn to single-purpose programs based on engineering tables or databases, particularly in small companies. Finite element method (FEM)-based tools for structural analysis are much less affordable. Also, the time required for FEM analysis is considerably longer than with other methods. As the available design completion times tend to be short, designers typically have to rely on specialized programs (MITCalc, KISSsoft, Autodesk Inventor or PREV). Consequently, they have no other choice but to accept the information and values obtained from these calculation programs, even without understanding their principles.

KEYWORDS

gear calculation, mesh, finite element analysis, root safety, flank safety

\section{INTRODUCTION}

The purpose of this study is to present the capabilities of the aforementioned affordable programs, the FEM method and analytical solutions in calculating and evaluating structural elements and mechanisms. One section of this paper is devoted to comparing the programs with respect to materials parameters, loading states, evaluation criteria and results. A detailed comparison was undertaken for a specific spur gear train. The gear strength analysis was carried out using analytical software tools [MITCalc 2003-2013, KISSsoft AG 1998-2014, and PREV 1992] and the finite element method. The results of these various approaches were compared. Different methods (based on applicable standards) may be employed in these calculations. Safety

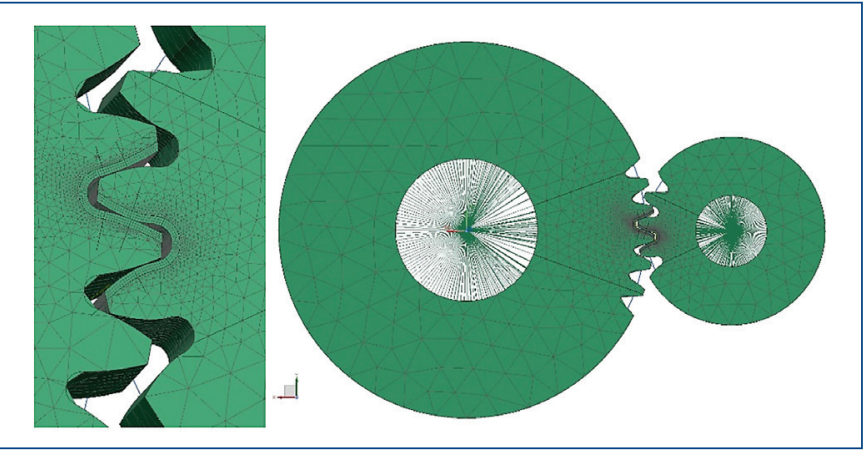

Figure 1. Mesh generation

\begin{tabular}{|c|c|c|c|c|}
\hline & Symbol & Units & $\begin{array}{c}\text { ČSN } \\
12050.6\end{array}$ & $\begin{array}{c}\text { C SN } \\
14220.4\end{array}$ \\
\hline Density & $\rho$ & {$\left[\mathrm{kg} / \mathrm{m}^{3}\right]$} & 7870 & 7870 \\
\hline Tensile Strength & $R m$ & {$[\mathrm{MPa}]$} & 640 & 785 \\
\hline Tensile Strength, Yield & $R e$ & {$[\mathrm{MPa}]$} & 390 & 588 \\
\hline Tooth Hardness - Core & $\mathrm{JHV}$ & {$[\mathrm{HV}]$} & 200 & 250 \\
\hline Tooth Hardness - Side & $\mathrm{VHV}$ & {$[\mathrm{HV}]$} & 0 & 650 \\
\hline Contact Fatigue Limit & $S_{\text {Hlim }}$ & {$[\mathrm{MPa}]$} & 520 & 1270 \\
\hline Bending Fatigue Limit & $S_{\text {Flim }}$ & {$[\mathrm{MPa}]$} & 410 & 700 \\
\hline Young's Modulus (Modulus of Elasticity) & $\mathrm{E}$ & {$[\mathrm{GPa}]$} & 206 & 206 \\
\hline Poison's Ratio & $v$ & {$[-]$} & 0.3 & 0.3 \\
\hline
\end{tabular}

Table 1. Input parameters for the strength check using the Inventor software, KISSsoft

\begin{tabular}{|c|c|c|c|c|}
\hline Parameter & Symbol & Unit & Pinion & Wheel \\
\hline Power & $P$ & {$[\mathrm{~kW}]$} & 3 & 2.971 \\
\hline Speed & $n$ & {$\left[\mathrm{~min}^{-1}\right]$} & 20 & 9.5 \\
\hline Number of teeth & $z$ & {$[-]$} & 20 & 42 \\
\hline Correction & $x_{1}$ & {$[-]$} & 0 & 0 \\
\hline Helix angle & $\beta$ & {$\left[{ }^{\circ}\right]$} & 0 & 0 \\
\hline Pure-rolling centre distance & $a_{\mathrm{w}}$ & {$[\mathrm{mm}]$} & \multicolumn{2}{|c|}{372} \\
\hline Gear ratio & $i$ & {$[-]$} & \multicolumn{2}{|c|}{2.1} \\
\hline Module & $m$ & {$[\mathrm{~mm}]$} & \multicolumn{2}{|c|}{12} \\
\hline Gear width & $b$ & {$[\mathrm{~mm}]$} & \multicolumn{2}{|c|}{80} \\
\hline Life & $L_{h}$ & {$[\mathrm{hrs}]$} & \multicolumn{2}{|c|}{5000} \\
\hline Material & & & 12050.6 & 14220.4 \\
\hline
\end{tabular}

Table 2. Input parameters for the strength check using the Inventor software, KISSsoft

factors may vary, depending on the gear shape, method of manufacture, life, notch sensitivity or load pattern. These factors affect the calculation of the contact fatigue strength, bending fatigue strength and the relevant allowed stress. Their ratios define the pitting $s_{H}$ and bending safety factors $s_{F}$. Those are the key parameters in gear design where failures due to pitting induced by the contact between the teeth and due to bending loads at the tooth root must be prevented. The finite element method calculation used here did not include the evaluation step. It was only employed to find the local stresses caused by the bending load at the tooth root and the pressure along the line of contact on the pitch circle. The conclusion compares the safety factors obtained by means of the various software programs. Stress levels calculated using the aforementioned programs and the FEM method are compared as well.

\section{Gear Wheel Parameters}

In order to check the gear wheel design with regard to pitting resistance and bending strength, one has to provide inputs including the wheel size, module, number of teeth, gear width and service load parameters, as shown in Table 2. These parameters were used for developing a 3D model and in calculations using KISSsoft, MITCalc and PREV programs. Detailed materials data for the pinion and the wheel are given in Table 1 which lists relevant materials characteristics. The wheel is made of the CSN 14220.4 steel and the pinion material is the CSN 12050.6 steel.

\section{Finite Element Analysis}

Gearing calculations using the FEM method are not often used when designing gear boxes in practice. In this case the numerical calculation was made as comparative. The contact task considering the linear behaviour of material took on a standard computer 10 minutes, the discretization error of the task, which is dependent on the fineness of the used network, was in normal below $10 \%$, so the results can be considered to be accurate enough for comparing with analytical calculations.

Figure 1 shows the meshes in both gears. For the calculation, it was necessary to define the shaft and its bedding points as infinitely rigid 
bodies. The ideal model of the shaft was built of 1D RBE2 elements. At the points of contact between the gears, fine mesh of CHEXA (20) elements was applied. In the tooth interior, CTETRA (10) elements were used. Transition regions between areas with dissimilar elements were built of pyramid elements. The torque is transmitted between the gears through contact areas on their teeth. If more accurate results were required, a non-linear analysis involving a bilinear characteristic of the sub-surface layer on the tooth face and flank would be necessary to use.

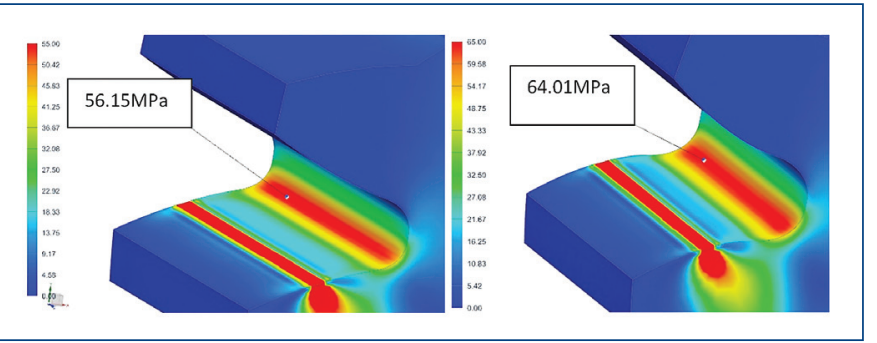

Figure 2. Bending stress at the tooth root in the pinion and the wheel

Using the FEM computation, bending stresses (at the tooth root) $\sigma_{F}$ and contact stresses (on the pitch circle) $\sigma_{H}$ were found in the pinion and the wheel. Ideally, these stress levels should be equal to those found by the analytical solution specified in the standard CSN 014686 [4] and corrected with applicable coefficients.

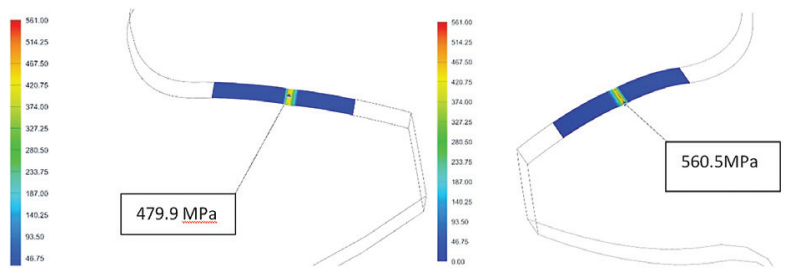

Figure 3. Contact stress on the pitch circle of the pinion and the wheel

\section{Comparison with Results of Calculations Using KISSsoft, MITCalc and PREV}

The purpose of this study is to acquire useful knowledge for checking the strength of gear wheels with the aid of affordable software tools. Calculation procedures for the examined programs are based on the CSN 014686 standard. This standard uses the Hertz pressure at the pitch point as the contact strength criterion.

The formula expressing the Hertz pressure at the pitch point is

$$
\sigma_{H}=\sigma_{H O} \cdot \sqrt{K_{H}},
$$

where $\sigma_{\mathrm{HO}}$ is the nominal contact stress

$$
\sigma_{H O}=Z_{E} \cdot Z_{H} \cdot Z_{\varepsilon} \cdot Z_{\beta} \cdot \sqrt{\frac{F_{o}}{b_{w} \cdot d_{1}} \cdot \frac{i+1}{i}}
$$

Where $K_{H}$ stands for the additional load factor, $F_{0}$ is the tangential force, $b_{w}$ is the gear train width, $d_{1}$ is the pitch circle diameter and $i$ stands for the gear ratio

$$
K_{H}=K_{A} \cdot K_{H v} \cdot K_{H \beta} \cdot K_{H \alpha}
$$

Calculation of the pitting safety factor $s_{H}$

$$
s_{H}=\frac{\sigma_{H l i m}}{\sigma_{H}} \cdot Z_{N} \cdot Z_{L} \cdot Z_{R} \cdot Z_{v}
$$

$$
\sigma_{F}=\frac{F_{o}}{b \cdot m_{n}} \cdot K_{F} \cdot Y_{F S} \cdot Y_{\beta} \cdot Y_{\varepsilon}
$$

Where $K_{F}$ denotes the additional load factor, $b$ is the wheel width, $m_{n}$ denotes the module, and $F$ stands for the tangential force

$$
K_{F}=K_{A} \cdot K_{F v} \cdot K_{F \beta} \cdot K_{F \alpha}
$$

Calculation of the bending safety factor $s_{F}$

\begin{tabular}{|c|c|c|c|c|}
\hline $\begin{array}{l}\text { Safety } \\
\text { factors }\end{array}$ & Name & PREV & $\begin{array}{c}\text { KISSsoft } \\
\text { ISO 6336:2006 } \\
\text { Method B }\end{array}$ & $\begin{array}{l}\text { MITCalc } \\
\text { ISO } 6336\end{array}$ \\
\hline $\mathrm{K}_{\mathrm{A}}$ & $\begin{array}{l}\text { Application } \\
\text { factor }\end{array}$ & 1 & 1 & 1 \\
\hline $\mathrm{K}_{\mathrm{Hv}}$ & $\begin{array}{l}\text { Dynamic } \\
\text { factor }\end{array}$ & 1.01 & 1.003 & 1.005 \\
\hline $\mathrm{K}_{\mathrm{H \beta}}$ & $\begin{array}{l}\text { Face load factor } \\
\text { (contact stress) }\end{array}$ & $1.2 / 1.27$ & 1.158 & 1.067 \\
\hline $\mathrm{K}_{\mathrm{Ha}}$ & $\begin{array}{l}\text { Transverse load factor } \\
\text { (contact stress) }\end{array}$ & 1 & 1.18 & 1 \\
\hline $\mathrm{K}_{\mathrm{F} \beta}$ & $\begin{array}{l}\text { Face load factor } \\
\text { (root stress) }\end{array}$ & $1.16 / 1.22$ & 1.107 & 1.054 \\
\hline $\mathrm{K}_{\mathrm{Fa}}$ & $\begin{array}{c}\text { Transverse load factor } \\
\text { (root stress) }\end{array}$ & $1.3 / 1.57$ & 1.18 & 1 \\
\hline \multicolumn{5}{|c|}{ For pitting safety calculation } \\
\hline$Z_{E}$ & $\begin{array}{l}\text { Elasticity } \\
\text { factor }\end{array}$ & 189.8 & 189.812 & 189.81 \\
\hline $\mathrm{Z}_{\mathrm{H}}$ & $\begin{array}{l}\text { Zone } \\
\text { factor }\end{array}$ & 2.495 & 2.495 & 2.495 \\
\hline $\mathrm{Z}_{\varepsilon}$ & $\begin{array}{l}\text { Contact ratio } \\
\text { factor }\end{array}$ & 0.89 & 0.887 & 0.887 \\
\hline $\mathrm{Z}_{\beta}$ & $\begin{array}{l}\text { Helix angle } \\
\text { factor }\end{array}$ & 1 & 1 & 1 \\
\hline $\mathrm{Z}_{\mathrm{N}}$ & $\begin{array}{c}\text { Life factor } \\
\text { for contact stress }\end{array}$ & 1.6 & $1.174 / 1.242$ & $1.236 / 1.331$ \\
\hline$Z_{L}$ & $\begin{array}{l}\text { Lubricant } \\
\text { factor }\end{array}$ & 1 & $1.025 / 1.02$ & $1.213 / 1.113$ \\
\hline$Z_{R}$ & $\begin{array}{c}\text { Roughness factor } \\
\text { affecting surface durability }\end{array}$ & 1 & $0.96 / 0.967$ & $0.84 / 0.911$ \\
\hline $\mathrm{z}_{\mathrm{v}}$ & $\begin{array}{l}\text { Peripheral } \\
\text { speed factor }\end{array}$ & 1 & $0.917 / 0.931$ & $0.877 / 0.942$ \\
\hline $\mathrm{Z}_{\mathrm{B}}$ & $\begin{array}{c}\text { Single pair } \\
\text { tooth contact factor }\end{array}$ & 1 & $1.06 / 1$ & $1.065 / 1$ \\
\hline $\mathrm{z}_{\mathrm{w}}$ & $\begin{array}{l}\text { Work hardening } \\
\text { factor }\end{array}$ & 1 & $1.051 / 1$ & 1 \\
\hline \multicolumn{5}{|c|}{ For bending safety calculation } \\
\hline $\mathrm{Y}_{\mathrm{Fa}}$ & $\begin{array}{l}\text { Form factor } \\
\text { (bending) }\end{array}$ & $2.8 / 2.37$ & $1.59 / 1.37$ & $3.036 / 2.593$ \\
\hline $\mathrm{Y}_{\mathrm{sa}}$ & $\begin{array}{l}\text { Stress correction } \\
\text { factor }\end{array}$ & $1.48 / 1.57$ & $1.82 / 1.99$ & $1.523 / 1.64$ \\
\hline $\mathrm{Y}_{\beta}$ & $\begin{array}{l}\text { Helix angle } \\
\text { factor }\end{array}$ & 1 & 1 & 1 \\
\hline $\mathrm{Y}_{\varepsilon}$ & $\begin{array}{c}\text { Contact ratio } \\
\text { factor }\end{array}$ & 0.69 & 1 & 0.707 \\
\hline$Y_{N}$ & $\begin{array}{l}\text { Life factor } \\
\text { for bending stress }\end{array}$ & $1 / 1.01$ & $0.986 / 1.006$ & $0.926 / 1.005$ \\
\hline$Y_{R}$ & $\begin{array}{l}\text { Tooth-root } \\
\text { surface factor }\end{array}$ & 0.957 & $0.957 / 0.957$ & $0.931 / 0.969$ \\
\hline$Y_{x}$ & $\begin{array}{l}\text { Size } \\
\text { factor }\end{array}$ & 1 & $0.958 / 0.93$ & $0.958 / 0.93$ \\
\hline$Y_{\delta}$ & $\begin{array}{l}\text { Notch sensitivity } \\
\text { factor }\end{array}$ & $1.07 / 1.11$ & $0.972 / 0.995$ & $0.976 / 0.992$ \\
\hline
\end{tabular}

$$
s_{F}=\frac{\sigma_{F l i m b}}{\sigma_{F}} \cdot Y_{N} \cdot Y_{R} \cdot Y_{X} \cdot Y_{\delta}
$$

The $Y, Z, K$ coefficients with relevant indices used in the formulas above are described in detail in Table 3, where their names, symbols and values in individual software programs are given.

Table 3. Inpuat parameters for the strength check using the Inventor, KISSsoft, and MITCalc software programs

The formulas for safety factor calculations are identical in all three software programs, as those are based on a single standard. The names of $Y, K$ and $Z$ coefficients (including applicable indices) are the 


\begin{tabular}{|c|c|c|c|c|c|c|}
\hline Stresses & FEM & KISSsoft & MITCalc & Discrepancy KISSsoft vs. FEM (\%) & Discrepancy MITCalc vs. FEM (\%) & Discrepancy MITCalc vs. KISSsoft (\%) \\
\hline$\sigma_{\mathrm{F}}$ & $64.01 \mathrm{MPa}$ & $58.76 \mathrm{MPa}$ & $43.1 \mathrm{MPa}$ & 8.2 & 32.66 & 26.65 \\
\hline$\sigma_{\mathrm{H}}$ & $560.5 \mathrm{MPa}$ & $560 \mathrm{MPa}$ & $443.5 \mathrm{MPa}$ & 0.08 & 20.87 & 20.80 \\
\hline$\sigma_{\mathrm{FG}}$ & $\mathrm{X}$ & $720.4 \mathrm{MPa}$ & $330.3 \mathrm{MPa}$ & $X$ & $X$ & 54.15 \\
\hline$\sigma_{\mathrm{HG}}$ & $\mathrm{X}$ & $578.19 \mathrm{MPa}$ & $574.1 \mathrm{MPa}$ & $X$ & $X$ & 37.52 \\
\hline
\end{tabular}

Table 4. Values and discrepancies between stresses in the pinion

\begin{tabular}{|c|c|c|c|c|c|c|}
\hline Stresses & FEM & KISSsoft & MITCalc & Discrepancy KISSsoft vs. FEM (\%) & Discrepancy MITCalc vs. FEM (\%) & Discrepancy MITCalc vs. KISSsoft (\%) \\
\hline$\sigma_{\mathrm{F}}$ & $56.15 \mathrm{MPa}$ & $55.47 \mathrm{MPa}$ & $39.66 \mathrm{MPa}$ & 1.21 & 29.36 & 28.5 \\
\hline$\sigma_{\mathrm{H}}$ & $479.9 \mathrm{MPa}$ & $526 \mathrm{MPa}$ & $416.7 \mathrm{MPa}$ & -9.60 & 13.16 & 20.77 \\
\hline$\sigma_{\mathrm{FG}}$ & $\mathrm{X}$ & $1247 \mathrm{MPa}$ & $628.91 \mathrm{MPa}$ & 49.56 & $X$ & 49.56 \\
\hline$\sigma_{\mathrm{HG}}$ & $\mathrm{X}$ & $1448 \mathrm{MPa}$ & $1615.6 \mathrm{MPa}$ & -11.57 & $X$ & -11.57 \\
\hline
\end{tabular}

Table 5. Values and discrepancies between stresses in the wheel

\begin{tabular}{|c|c|c|c|c|c|c|}
\hline Safety factors & KISSsoft & MITCalc & PREV & Discrepancy KISSsoft vs. PREV (\%) & Discrepancy KISSsoft vs. MITCalc (\%) & Discrepancy MITCalc vs. PREV (\%) \\
\hline$S_{F}$ & 12.26 & 7.66 & 7.55 & 38.41 & 37.52 & 1.43 \\
\hline$S_{H}$ & 1.03 & 1.29 & 1.36 & -32.03 & -25.24 & -5.42 \\
\hline
\end{tabular}

Table 6. Values and discrepancies between pitting and bending safety factors in the pinion

\begin{tabular}{|c|c|c|c|c|c|c|}
\hline Safety factors & KISSsoft & MITCalc & PREV & Discrepancy KISSsoft vs. PREV (\%) & Discrepancy KISSsoft vs. MITCalc (\%) & Discrepancy MITCalc vs. PREV (\%) \\
\hline$S_{F}$ & 22.49 & 15.86 & 12.66 & 43.7 & 29.47 & 20.17 \\
\hline$S_{H}$ & 2.75 & 3.88 & 3.98 & -44.72 & -41.09 \\
\hline
\end{tabular}

Table 7. Values and discrepancies between pitting and bending safety factors in the wheel

same in most cases. Some coefficients, however, may have different names. The differences, for the most part, are only in their symbols or, perhaps, there may be different combinations of coefficients in the various software programs.

More substantial differences are encountered in the calculation of allowed stresses - tooth-root stress limit $\sigma_{\mathrm{FG}}$ and pitting stress limit $\sigma_{\mathrm{HG}}$. Minor differences can be found in nominal stress calculations. In general, the software programs use identical methods for determining the forces against the teeth but differ in the values of coefficients and, most importantly, in the stress evaluation. Stress results are summarized in Table 4 and 5.

The above-listed pitting and bending safety factors given in Tables 6 and 7 are comparable in MITCalc and PREV software tools. The bending safety factor in KISSsoft differs more substantially from those in the other programs. On the other hand, the pitting safety factor is comparable with the others. The differences are due to the $Y_{\mathrm{Fa}}$ - Form factor (bending). It affects the calculation of the $Y_{F S}$ coefficient and, in turn, the stress and safety factor magnitudes. Table 3 shows that its value is approximately twice lower in KISSsoft than in MITCalc and PREV. The discrepancies in values of both safety factors are caused by the coefficients defined in particular software programs or by the limitations on the selection of coefficient values.

The software programs also recommend certain minimum levels of pitting $\mathrm{S}_{\mathrm{Hmin}}$ and bending $\mathrm{S}_{\mathrm{Fmin}}$ safety factors. In MITCalc and PREV, these limit values are approximately equal. KISSsoft, however, suggests substantially lower values. The minimum safety factor levels are the engineering designer's choice.

\begin{tabular}{|c|c|c|}
\hline & $S_{\text {Hin }}$ & $S_{\text {Fmin }}$ \\
\hline KISSsoft & 1 & 1.4 \\
\hline MITCalc & 1.3 & 1.6 \\
\hline PREV & 1.2 & 1.7 \\
\hline
\end{tabular}

Table 8. Recommended minimum factors of safety for pitting and bending in individual software programs

\section{CONCLUSION}

The merits of the present paper include the comparison of results using different software programs for gearing designs. During stress calculation at the tooth root $\sigma_{\mathrm{F}}$ and on the pitch circle $\sigma_{H}$ the KISSsoft program corresponds to the FEM results. The MITCalc program shows a greater discrepancy, the calculated voltage is lower. For both analytical calculations further allowable stress in contact and bending is defined $\left(\sigma_{\mathrm{Fg}}\right.$ and $\left.\sigma_{\mathrm{Hg}}\right)$. The largest discrepancies were found between the $\sigma_{F G}$ values. Here, the difference between KISSsoft and MITCalc results is twice as large. This is no random result. A number of followup calculations were carried out. In all cases, identical differences between $\sigma_{\mathrm{FG}}$ values obtained with KISSsoft and MITCalc programs were obtained. The question is if it is not just an error in the program. However, this important difference of values has a direct impact on the resulting bending safety factor $S_{F}$ and increases the final dimensions. From this point of view we can say that the differences between the results obtained by analytical calculations are not fundamental. However, using the MitCalc program is conservative and the designed gears using this program are the most robust.

\section{ACKNOWLEDGEMENTS}

The work has been supported by Department of Machine Design (University of West Bohemia).

\section{REFERENCES}

[CNI 1998] Czech Normalization Istitute, CSN 01 4686-3. Strength calculation of helical and bevel gears. The control calculation of helical gears (in Czech), Prague: 1998

[KISSsoft AG1998-2014] KISSsoft, Bubikon: Available at: www.kisssoft.ch/ english/downloads/, 1998-2014.

[MITCalc 2003-2013] MITCalc 1.7, Available at: www.mitcalc.com/en/ products.htm, 2003-2013.

[PREV 1992] Skoda Machine Tool a.s., PREV (company proprietary software), Pilsen, 1992

\section{CONTACTS}

Assoc. Prof. Ing. Vaclava Lasova, Ph.D.

University of West Bohemia, Department of Machine Design

Univerzitni 22, Pilsen, 30614, Czech Republic

tel.: + 420377638 200, e-mail: lasova@kks.zcu.cz,www.kks.zcu.cz 